\title{
Importance of Technical and Professional Writing Certificate Program in a Japanese Computer Science Context
}

\author{
Debopriyo Roy* and Banri Yasui \\ The Univers ity of Aizu, Aizuwakamatsu-shi, Fukushima, Japan
}

\begin{abstract}
Technical communication (TC) as a subject, and more so a department in the university curriculum are few and far between in the Japanese educational context, even with STEM education. As part of this paper, an exploratory pilot study is described explaining the overall importance of such a TC certificate program and how an optional TC feeder course could help students understand the value of the TC and professional communication (PC) discipline for a typical Japanese computer science academic context, in preparation for the job market. Further, such a TC-focused introductory feeder course helps the university administration, students and teachers better understand how computer science as a discipline should also emphasize on technical and professional writing and communication skills in the language curriculum, for better project management, and helping students develop soft skills for the market. Further, another strong argument for such coursework (offered in English as a medium of instruction) is also related to developing students' entrepreneurial and transition skills for the market. This paper highlighted on one such rare certificate program and feeder course in the computer science (CS) department of a Japanese technical university which helped students understand the scope of the market, how technical communication as a discipline has wide-ranging opportunities, besides helping students develop basic understanding of content areas such as manual and information design, usability, content management and delivery, technical language, visualisation etc. Finally, the paper ends with a discussion of a few of the well-known TC certificate programs and TC organizational infrastructure in the US academia, and how we can catch up with that trend in Japanese higher education.
\end{abstract}

Keywords: technical communication, design, curriculum, entrepreneurship, certificate

\section{Introduction}

There are numerous technical communication (TC) programs that are now part of the university curriculum especially for STEM students. It's becoming more commonplace with the emergence and importance of soft skills training in universities. Soft skills are incredibly important when preparing students for the job market. It's very difficult to define soft skills as concepts because that can neither be defined formally nor evaluated adequately. Generally, research has mentioned teaching computer science soft skills as soft concepts to include genres such as (1) software and its engineering (2) software creation and management (3) collaboration in software development and (4) programming teams [1]. However, that leaves out TC as a genre that is generally designed to support and develop both linguistic competence and communication skills in students.

A survey of 73 top-ranked U.S. and Canadian engineering schools examined initiatives that engineering schools are putting in place to improve communication instruction for their students. The investigation revealed that $50 \%$ of the U.S. schools and $80 \%$ of the Canadian schools require a course in technical communication. About $33 \%$ of the schools utilize some form of integrated communication instruction, and another $33 \%$ offer elective courses in communication [2]. Establishing engineering communication centers in universities and communication-across-the curriculum teaching approach is becoming more of a movement in STEM departments, especially in western universities.

In this context, it's also important to mention that globalization and multinational coordination is radically transforming technical communication (TC) both in the workplace and in higher education [3]. Following on this research, the idea is to integrate a high level of activity, planning, and interest in creative and innovative global

*Corresponding author: $\underline{\text { drov@u-aizu.ac.jp }}$ 
partnerships that provides an opportunity to systematically integrate experiential learning, collaborative international research, and civic engagement in the TC curriculum.

Interestingly, proper TC certificate programs in Japan that include courses in information architecture, usability, $\mathrm{HCI}$, programming and algorithm, content management and delivery, information design and digital storytelling skills using CAD and other media design software are almost non-existent. The reference here is more on TC programs that cater to technical students with more technically-focused TC courses, and not only on courses offered in the English departments in universities with the broad focus on language-focused organization, editing and documentation skills, including design and social media use, and organizational, negotiations and teamwork focused genres. Another interesting point to mention in this context is that hardly any (if any) university in Japan has established a technical communication department, although statistics argue that demand for technical writers in the Japanese industry scenario, which is largely export-driven is likely to increase multifold over the next decade. There could be administrative and social reasons explaining the dearth of such programs or departments, including lack of expert faculty in the area, students lacking English levels good enough to learn technical communication in English (although the field is independent of language and technical communication could well be learnt in Japanese as well), lack of interest in the field including lack of marketing/promotion on the part of the university administration, and lack of interconnectedness and interdependence, and coordination between industry and academia that will allow establishment of such programs.

This brings us to the discussion of how the Japanese Technical Communication Association (JTCA) is coordinating with universities in Japan to introduce TC certificate programs which will allow students to gain additional expertise in preparation for the job market. Technical communication certificates/programs are offered by many universities, especially in the western countries such as the US, Germany etc, as an alternative to full undergraduate or graduate degrees in the field. There are numerous such TC certificate programs right now in the US, but the literature is scant and there is a huge void in systematic information about such programs and its effectiveness. However, in this context, it must be mentioned that many of the US certificate programs are offered as an independent degree, and is not required to be earned concurrently with another degree (however, programs could prerequire a degree for admission to the program) [4].

As part of this study, the article highlighted a specific TC comprehensive certificate program, and an optional 1-credit elective course offered at a technical computer science university (Univ. of Aizu) in Japan in preparing the students with additional and productive communicative and technical competence to support market requirements and provide a competitive advantage as a candidate in the job market. Currently only two universities in Japan have the approval for this certificate program.

Specifically, the article discussed an optional SCCP course design (a non-credit undergraduate course on special topics) that provided a summary of a few representative skills that we want students to master in preparation for the certificate. These representative assignments in the SCCP course have been designed to trigger interest in the computer science students and allow them to get a feel for the types of assignments they might be responsible for in the industry either working as a software professional and/or as a technical writer. This special course is being offered for the first time in the academic year 2020, and the single student who enrolled in the course offered some insight into both a representative understanding of a typical undergraduate computer science students' ability to respond to such assignments in English, and also get a feel for how they might do with industry-focused short TC assignments.

\section{The TC Certificate Program at the Univ. of Aizu}

The University of Aizu offers a comprehensive professional 18-credit technical communication certificate course for the undergraduate computer science students at the University of Aizu. A professional certificate of completion is presented by the Japan Technical Communicators Association (JTCA - a public incorporated foundation comprised of technical communication specialists). This unique technical communication program - one of its kind in a computer science program in Japan allows students to learn how to produce and communicate technical information using traditional and digital technologies. The professional technical writing certificate is designed to show a level of commitment and excellence for the potential applicant in the job market that impresses employers. This professional certificate is designed to show employers that students have the necessary language and communication ability in the target language, specialized training, and knowledge to synthesize technical information in a specialized area. In typical technical communication tasks, one often needs to create pieces for review or publication, use an editing software, understand the basics of content management and document production, and perform document testing to ensure technical information is communicated clearly and concisely. Clear, concise, and effective writing is always important; in the technical fields, it's critical. 
Table 1. Demonstrated the layout of the certificate program

\begin{tabular}{|l|c|}
\hline Categories & Credits \\
\hline Basic Technical Communication & 2 \\
\hline Information Gathering and Analysis & 2 \\
\hline Information Architecture & 2 \\
\hline Production Management \& Direction of the Production Process & 2 \\
\hline Visualization \& Expression Design & 4 \\
\hline Writing in English and Japanese & 2 \\
\hline Peripheral Domains - User Interface, Compliance \& Understanding Foreign Cultures & 18 \\
\hline TOTAL (Undergraduate Credits) & 2 \\
\hline
\end{tabular}

https://www.u-aizu.ac.jp/en/curriculum/TC/ (Official TC Certificate Program Webpage of the Univ. of Aizu)

The certificate is issued by the Japan Technical Communicators Association (JTCA) after a student passes the approved 18-credits of coursework as mentioned above, and applies for a certificate. The advantage of this certificate program is that there is no extra effort to earn this certificate because the student will simply need to choose a selected set from the standard set of courses which are part of the existing university computer science program curriculum. Awareness of a problem in general and written communication skills for computer scientists is growing, as evidenced by its increasing prominence in computer science curricular recommendations. TOEIC exam scores which are often required for by the companies in Japan, taken by Japanese students in the university or for job hunting does not in any way guarantee professional and technical writing or communication ability. Most universities in Japan do not have a concrete plan to support student communication needs in preparation for the industry, or internships. In other words, there are no systematic transfer skills development with such an example of TC certificate program. The IEEE (Computing Curriculum Efforts) stressed the importance of including the mechanics and process of writing, acquiring the ability to communicate ideas effectively, and integrating these skills into the entire computer science program. This certificate identifies and includes only those courses that are related to analytical reasoning and technical writing, including understanding of educational technology, technical and professional presentations, information architecture, production processes and intercultural communication etc. The student gets a professional certificate as an added qualification and could be used during the job search process. The student taking the certificate can potentially build up industry connections by attending the annual JTCA conferences, and other associated TC-related activities on campus.

The following professional communication skills are expected at a reasonable or moderate level, at the least, as a natural outcome from taking the certificate courses:

- Ability to communicate and network in the industry

- Ability to secure job interviews

- Ability to secure internship opportunities

- Ability to negotiate and discuss an issue smoothly

- Ability to show self-confidence and knowledge of the field

- Ability to explain a problem or come up with a possible idea for solution

So, why are technical communication specialists needed in an organization?

- A high-quality, well-versed documentation and manuals reflect well on the organization.

- Technical writers can understand complex content from the viewpoint of industry experts and average consumers.

- Professional technical writers have the skill and knowledge necessary to complete an end product faster with the specific needs of the product market in mind. 
- Technical writing can be concise, impartial, state facts clearly, and allow end-users to read exactly what they get.

- From the document layout/font to appropriate chart size, a technical writer can make the content look professional.

What students are expected to learn:

- The basic fundamentals of technical communication, such as audience analysis, document production, usability,

electronic forms of communication, technical styles etc

- Basics of technical editing, including grammar and understanding style guides

- Develop information design skills for technical communicators and learn how to write technical online documents while addressing information design standards

- Critical thinking and identifying major questions, assumptions, interpretations and conclusions, and application of criteria and standards to technical analysis

The program is designed for computer science (CS) majors:

- who will be working on international projects and dealing with international clients, competitors and vendors

- who will write in their future employment

- whose job will involve understanding and interpreting technical documents

- who will have to design technical documents for print and online delivery

- whose job will involve dynamic document production and delivery online

- who will have to design visuals and make technical presentations for their projects

\section{The SCCP Course Design}

This SCCP optional course (which is generally taken in the 3rd year of the computer science program) introduces students to the idea of this professional certificate program and the advantages of having such a professional certificate for the job market, to further support their computer science credentials. The course covered 8 major introductory themes and related assignments which were geared towards introducing students to the field of technical communication, and the certificate program, in general. The following themes were part of the coursework.

- Introduction to the Professional TC Certificate

- Working as a Technical Writer in the Job Market

- Technical Writing Jobs in Different Industries

- Case Study: Technical Writing in the Aviation Industry

- Why Software Developers Should Know Technical Writing

- Understanding Data Visualization in Technical Documents

- Understanding Professional Documents in TW Industry

- Professional Presentation at an International Conference

SCCP Assignments: The next section outlined the typical assignments in the SCCP feeder course, and a typical representative response from a student who went on to complete the assignments while preparing to complete the actual TC certificate course. As part of this SCCP course, students wrote several short reports.

The first three short report assignments (first three themes) mainly focused on lectures and discussions related to the certificate program, types of courses in the certificate, future expectation in the job market, motivation for the certificate as a computer science major, student understanding about working as a technical writer in the job market, desire to work in a certain kind of industry and understanding about the required skill set etc. From the 4th assignment onwards (4-7 themes), the course was designed to start with assignments that led to the understanding of how to design technical documents such as user manuals, visualisation design, and professional communication skills. The 4-7 themes were mainly focused on providing students with some basic idea about the kind of content research necessary to be a technical writer, and the kind of documentation and software skills necessary.

\subsection{Short Report Assignment 1: Introduction to Technical Writer \& Benefits for Computer Science Majors}

This was the first week of the SCCP course, and the TC comprehensive certificate program was explained in detail, along with an introduction to the field, and what's in there for computer science majors. This assignment followed 
after an intense session introducing the field of technical communication, and how this feeder course, and the TC certificate specifically could prove immensely beneficial for computer science students. Below is a typical response for the above questions, which highlights the mindset of a junior-level undergraduate computer science student.

Short Report Assignment: Please understand the FULL scope of the TC certificate program and what it means.

Now write a short 200-250 words or more report, explaining the following:

1. Are you interested in the TC certificate program? If yes, why? If no, why not? (30-words)

2. What is the value as you see of a TC certificate program for CS majors, like the one we are discussing here? (75-words)

3. What could be the motivation for CS students to enroll in this SCCP? What is your expectation? (30 words)

4. Why do you think technical writing skills are important for computer science professionals? (50 words)

5. Submit an article link that you studied in English from Google search which talks about the importance of technical writing in the industry. Why is this article important? (40 words)

6. Find a few TC certificate programs from around the world and discuss what it offers? (50 words)

Firstly, I don't only want to work in Japan but have many countries in my mind. And now, I have an objective to start a new company in Japan and a major firm out of Japan as well. So I have an interest in the TC certificate program. Participating in the TC certificate program, CS majors can develop an overall expertise beyond CS, and they won't need to bother about getting a suitable job, and won't be troubled about their income. For example, people who live in the country without much opportunity to get a job or people who have a dream to go around the world could feel happier and may find it useful to be a technical writer. In the process of applying for, and taking the technical writing certificate, this SCCP course could add to the motivation of CS students. They will find the value of such certificates when applying for job interviews or joining a company. That's my expectation with this SCCP. There are two aspects that show technical writing skills are important for computer science professionals. First, when computer science professionals make a program or want to discuss software/hardware etc. with foreigners, they need to talk with the foreigner about technical issues. Basically, the person who can't write about technical issues can't talk with foreigners about professional things. Second, companies renew or make their merchandise, and computer science professionals could be required to explain their new merchandise in this situation in order to keep their customers. This article, "Technical Writing and Computer Programming”, written by Judith Kaufman shows how technical writing and computer programming complements each other. We can learn both and find a better way to study technical writing. SIMON FRASER UNIVERSITY teaches all of the core technical communication competencies that the Society for Technical Communication has identified. Their technical writing courses identified that students could master key technical communication skills such as technical writing and editing, research analysis, information design, indexing, documentation project management, online documentation, desktop publishing applications and more.

\subsection{Short Report Assignment 2: Working as a Technical Writer in the Job Market}

This was the second week of the SCCP course, and the focus was on an intense discussion about the technical writing job market and the outlook in Japan, and in several countries including the US. Discussions focused on salary, required skill set, and the typical work schedule in specific technical writing industries. Students watched YouTube videos about a typical technical writer's job schedule, studied job advertisements, salary scales etc.

Short Report Assignment: Please watch the 33-minutes video about the technical writing job market explaining the regular qualification of a technical writer, and the job expectations in the market.

Also, go through the occupational profile of a regular technical writer.

Now, write a short 200-250 words or more report explaining the following:

Q1. Do you have an interest in working in the TC job market? If yes, why? If no, why not?

Q2. How are technical writing skills a VALUE ADDITION in the computer science job market?

Q3. What are some of the basic issues you understood based on the video you watched?

Q4. What are some of the basic issues you understood based on the link we studied?

I have much interest in working in the TC job market, for I want to launch an ICT venture company in a country that speaks English in the future, and I thought technical writing skills will be vital if I provide services in and out of my homeland. Technical writing skills give a large benefit in the computer science 
job market. For example, when you provide your product in another country, a computer science worker should possess the technical writing skills to write an appropriate explanation of the product-for which they know much. Also, one needs to write in the appropriate method or procedure that suits the particular country. I understand the TC job market is getting bigger and bigger because technical writers are expected to communicate about technical issues with other countries for their multinational products and also, they need to write the use, repair and maintenance instructions for new merchandises and update information for new and existing merchandise using different media platforms and output forms. Moreover, it was important for me to understand the work environment of a technical writer and how to become a technical writer. Most technical writers work full time, and they work in a variety of industries, they are concentrated in the computer and management, scientific, and technical industries. Technical writers usually have a college degree and knowledge of or experience with a technical subject, such as science or engineering.

\subsection{Short Report Assignment 3: Technical Writing Jobs in Different Industries/Different Technical Writing Specialties}

The third week focused on technical writing jobs in different industries, including specialised areas such as technical editors, technical copywriting, technical proposal writing, technical communication consultant, technical content contributor, technical marketing writer, technical creative writing, and operations technical writing.

Based on the lecture notes from today's class, write short 200-250 words or more report explaining the following: Q1. Which industry do you think you would fit in considering your interest, future education, and related qualifications?

Q2. If you were to work in a certain industry as a technical writer, what industry-specific knowledge would you need to have? - Give an example from a specific industry type. ${ }^{*}$, Do your research from job advertisements and other sources.

Q3. Design a one-page professional marketing information guide with https:/www.canva.com/ putting the Q2 response as a professional guide that could be marketed for professional communication purposes.

I think I would fit in the software industry and engineering industry, for I want to launch the company regarding software, and I want to expand the company to the whole world. So, I need to earn the TC certificate so that I can use it for my company. In addition, I can use a range of computer programming languages well, for example python, JavaScript. So, I want to get a TC certificate related to computer programming skill in order to acquire the advantage of entrance examination in case I try to belong to some company. As for the Software industry, it needs the following three skills. First, Bachelor's degree or relevant experience. Second, ability to read and write basic example code in at least one of the more popular programming languages on the market, such as Java, JavaScript, Python, C++, C\#, Swift, or Kotlin. Third, experience of writing for developers and technical audiences - blog, product documentation, technical information. As for the Engineering industry, it needs the following six skills. First, Bachelor's degree in math, science or engineering from an accredited four-year university plus 2 or more years of relevant experience, or equivalent thereof. Second, technical writing experience in producing forensic engineering reports. Third, Civil/Structural Engineer or Technician, with experience in forensic engineering, including site inspections and subsequent reporting. Fourth, Professional Engineering license or Engineer-In-Training status a plus. Fifth, must have advanced knowledge of MS Word. Sixth, excellent written and oral communication skills.

As could be noticed from the short report above, that students are also taught how to search for relevant information from the web on specific topics and use it in the report, by rephrasing.

The following brochure has been designed by the student in the SCCP course highlighting a typical technical writing industry job position, and with the aim of making other students aware of the skill set required and employer expectations for the position. In the process of designing this brochure, the idea was also to teach students the art of organizing such information, layout, formatting and associated details from a marketing and promotional point of view. 


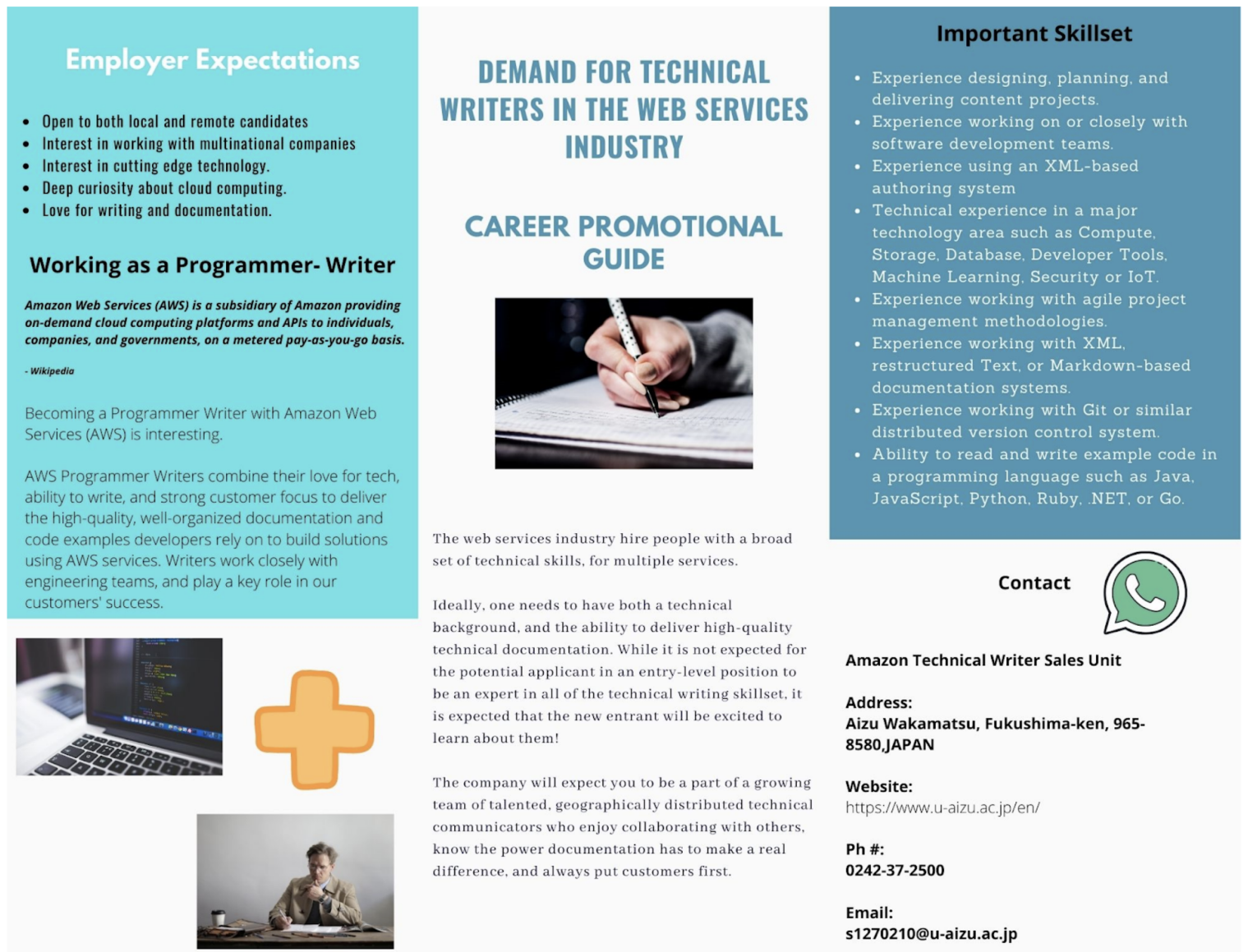

Figure 1. TW Brochure Designed by a SCCP Student (Brochure to Advertise Demand for Technical Writers)

\subsection{Short Report Assignment 4: Developing preliminary ideas about the complex nature of the manual design in the aviation industry}

The fourth week focused on a specific case study in the aviation industry (as a representative example) whereby the student was made to scan through a variety of aviation-related technical user manuals and user guides to get an idea about the complexities related to the design of aviation user manuals.

The following assignment was handled during this week.

Read the link carefully: https://instrktiv.com/en/how-to-write-a-manual/

Section \# 1: $5 \%$

Please study the aviation link provided with this class.

Now, write a short 100-words or more report explaining the WRITING and ORGANIZATIONAL challenges faced by a technical writer when designing such documents. What nature of content complexity and writing styles are we talking about? What are some of the essential qualities that a technical writer must have when writing such documents?

\section{Section \# 2: 10\%}

Based on the information provided on the aviation manuals list and link, design a 2-page technical report with pictures (100-125 words approx. using CANVA) introducing the challenge for documentation in the aviation industry. No need to talk about the challenges with specific examples from the aviation manual as such, but provide a summary of the information, based on what you could read and understand from the link.

Section \# 3: $10 \%$

Try to design an online technical manual using the aviation industry links with the following software: https://www.manula.com/ 
Then, explain how the manual software works with voiceover using https://screencast-o-matic.com/

* Use the 7-day trial version
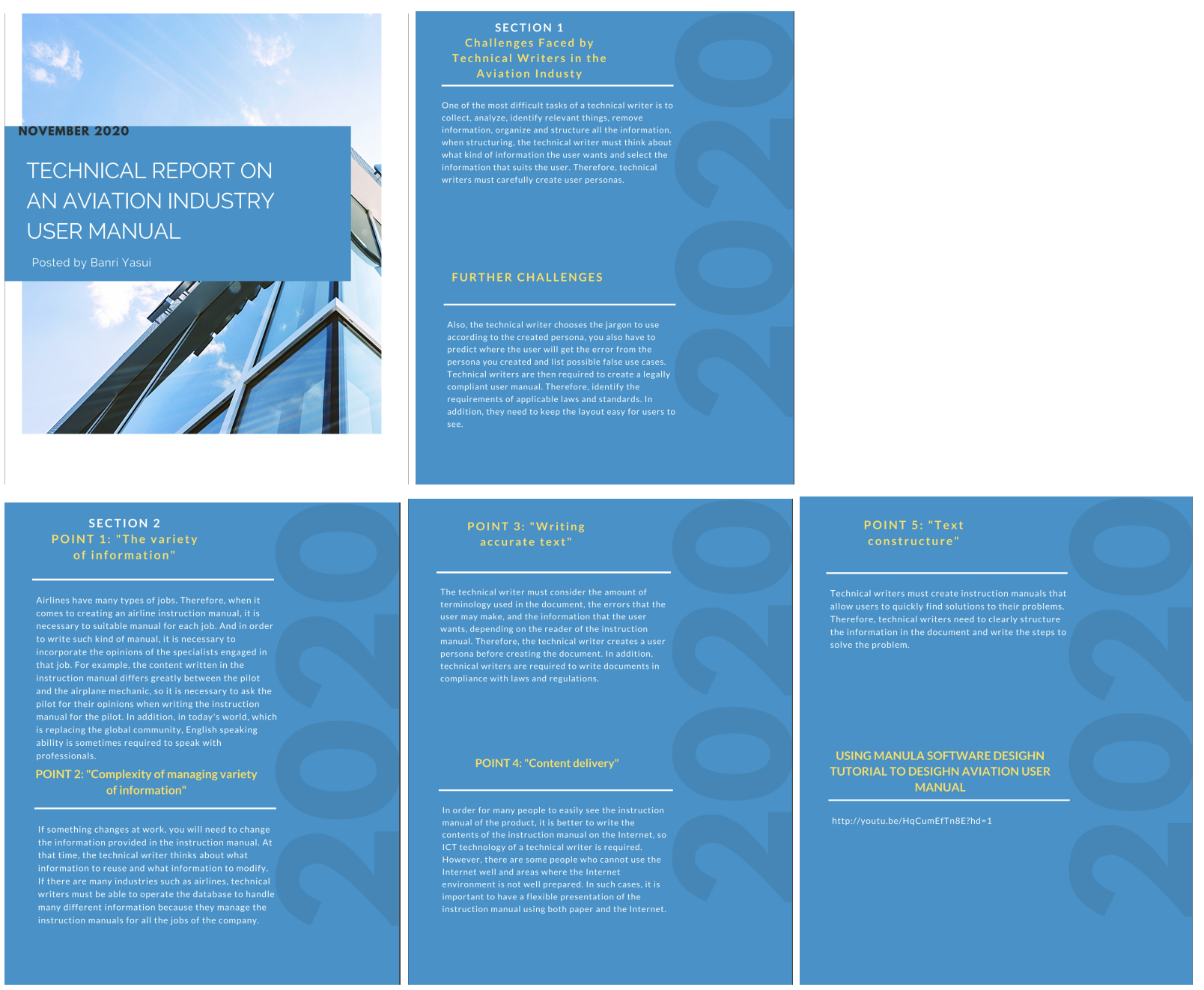

Figure 2. Short Report Explaining the First Impression about the Aviation Industry Manuals

The purpose with the Figure 2 short report was not to go very deep into understanding the aviation industry user manuals, but basically tried to form an initial first impression about the complexities as is seen for a 3rd year undergraduate computer science student for whom English is a foreign language. The report should be read in that perspective.

\subsection{Short Report Assignment 5: Data Visualisation with Tableau}

The fifth week focused on providing an elementary exposure for students to understand the range of visualization tools very frequently used by technical writers to showcase and demonstrate data, pattern, frequency etc.

The following assignment was planned as part of this week:

Open a trial account with https://www.tableau.com/trial/visualize-your-data and DOWNLOAD the free version.

Now, study the interface first to understand the different data visualization options available.

Practice: Then, use some fictitious data with at least two really innovative types of applications to learn how to use the program. * The trial version is valid for 14 days.

Assignment:

1. What did you like about the program? (50-words)

2. Explain at least three good applications that you think you could use in the future? Show screenshots. (150 words@50 words per application)

3. Watch the Getting Started video. Explain the major points mentioned in the video. (50 words) 
4. Watch the Visual Analytics video. Explain the major points mentioned in the video. (50 words)

5. Watch the Connecting to Data video.

6. Explain the major points mentioned in the video. (50 words)

7. Why do you think this program could be a very important tool for technical writers? (50 words)
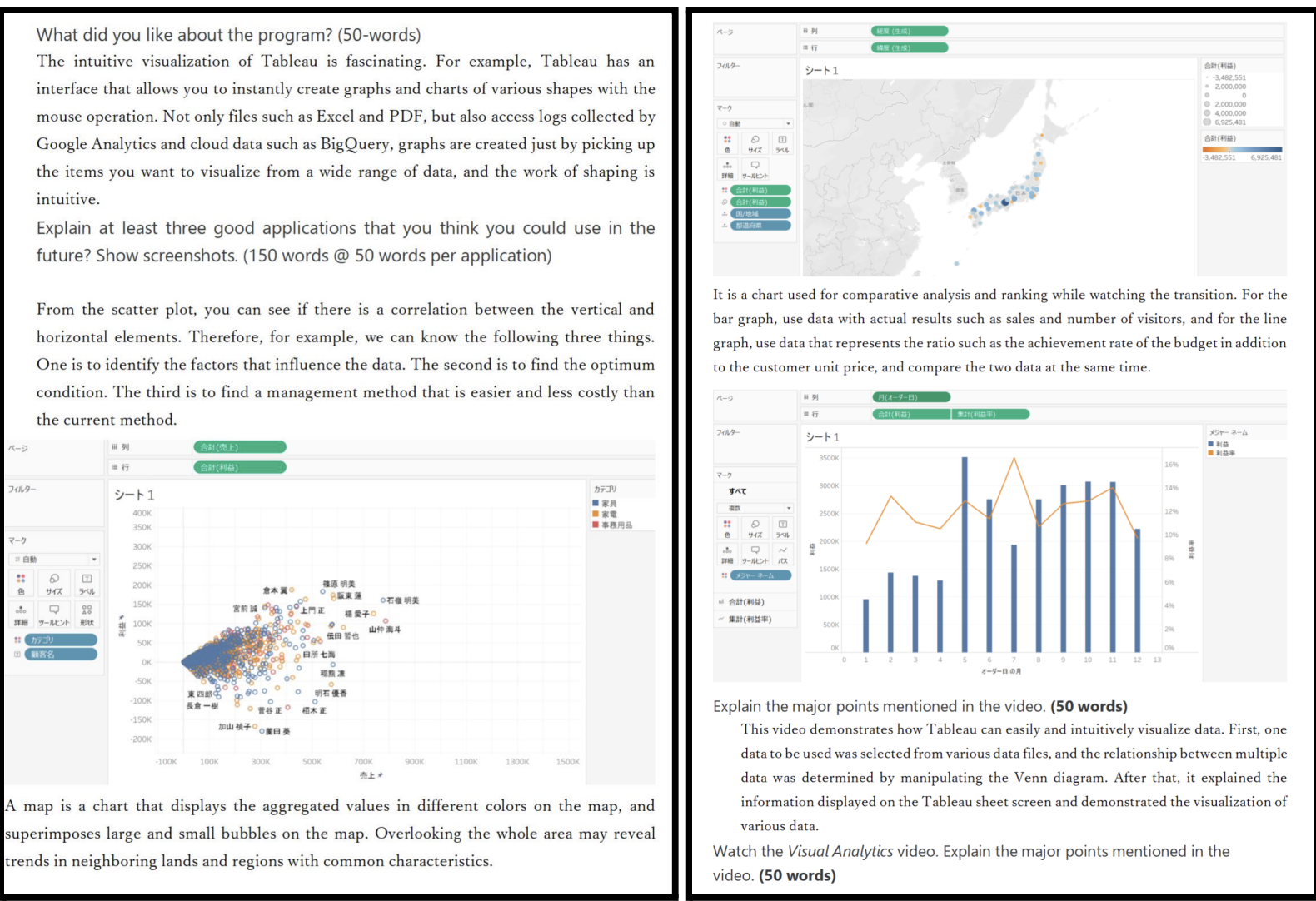

Tableau allows you to connect with data analysis tools. And you can edit the imported file data in Tableau. Tableau introduces videos and blogs that explain the basics of using Tableau. In addition, Tableau has an animation function, for example, you can see the fluctuation of data from day to day as an animation.

Explain the major points mentioned in the video. (50 words)

Tableau is very useful at visualizing data. You can import various data files. "Dimension"

refers to the characteristics of the data, such as categories and customer names. And "Measure" refers to a number. Therefore, when you make a diagram, "Measure" is plotted values and "Dimension" has the role of classifying the plotted values.

Why do you think this program could be a very important tool for technical writers? (50 words)

Technical writers may display data about the product when creating the instruction manual for the product. At such times, technical writers should be able to quickly create data that is easier for customers to see. Also, when processing a large amount of data, such as when analyzing customer characteristics, it is necessary to visualize the data and analyze the data.

Figure 3. Report demonstrating preliminary understanding of the Tableau software and its benefits in technical writing (page 1-3)

It's important to understand that the purpose of this SCCP course is to introduce students to the field of technical communication at a very elementary level, and provide a solid understanding of the nature of basic technical writing skill set that is required in most industries where the student is likely to work as a computer science specialist (e.g., software developer) or a professional technical writer with a computer science background. The course did not provide much opportunity for sustained development of any specific skill-based domain in technical writing. So, it's best to see this course as providing a birds-eye view of the desired basic skill set needed as a technical writer. So, expectedly, this course was not suited to dig deeper into specific programs and applications related to more technical 
issues such as content management and delivery systems, and other design and information architecture software which are typical use case scenarios for technical writers, and probably more so for technical writers with a computer science background.

\section{Discussion \& Conclusion}

It's better to see this paper as providing an overview of how to get started on a technical communication journey in a Japanese university context, where technical communication in the university and technical communication as a collaborative field between academia and industry is still at its infancy.

TPC Certificates/Programs in the US \& Germany: So, in this context, it's more important to focus on a few major TC certificate programs from the United States, and explore the difference between the two situations. The section will discuss how the Univ. of Aizu TC certificate program is different from those programs, and the reasons behind the difference. Fundamental differences between the Univ. of Aizu TC certificate program and the majority of the certificate programs from US universities mentioned below are as follows: (1) Students in the US will undertake this program in their native language (2) the US TC programs are generally more specific with a much wider range of specific TC courses available and (3) it assumes more student experience about the field in general and more writing background and (4) many of these programs are not highly technical in nature (e.g., programming skills are not as much needed). In comparison, for the UoA, the students are undergraduate CS students with low-moderate English language ability, and the entire 18-credit certificate includes recommended CS courses, and many other social science, and applied linguistics focused courses. So, it's a little different in terms of the focus areas, more comprehensive in a way, but is not focused entirely on developing the following skills such as the ones mentioned with the Univ. of Washington program:

https://www.pce.uw.edu/certificates/professional-technical-writing

Further, as a preliminary attempt at introducing a TC certificate program, Japanese universities may not be in a position to go for more specialised grouping of TC certificate programs similar to what has been mentioned on the Richmond University website.

https://spcs.richmond.edu/noncredit/programs/technical-writing/index.html

The UC Berkeley Extension sponsored/hosted Professional Writing Program has a range of interesting non CS-based courses on offer that uses different visual, social and information design toolset and media, for example, writing for social media, screenwriting: the art of visual storytelling etc.

https://extension.berkeley.edu/search/publicCourseSearchDetails.do;jsessionid=2E85C56E3CC81F0EB49CF9B655 E0124C? method $=$ load\&courseId=41378\#connectedCertificateDetails 17210

However, it's difficult to implement such courses at the UoA without having such a range of dedicated TC courses, and a department in the broad subject area and/or having faculty members in those specialised areas. Technical universities such as the UoA may explore the opportunity to construct a department or center focused on applied linguistics, professional and technical communication, language applications and technical communication, language and new media as part of the school of computer science and engineering. Such departments or centers or tracks could also be developed for the graduate school only. This can only happen with technical and professional communication is seen as an allied computer science discipline. Such a mindset has to develop from consulting a framework in which to teach (technical) communication to computer science majors [5].

Another important program which is, and could be very closely aligned and relevant for computer science students and computer science labs at the UoA is from a partner university - HSKA, Germany.

https://www.hs-karlsruhe.de/en/faculties/information-management-media

This faculty do not offer a certificate program, but the courses on offer are mostly very closely aligned to different computer science areas such as programming, information architecture, design, database and big data management etc. One possible example of a certificate program which could be developed in collaboration with HSKA, Germany which is a partner university with UoA is in new media and TC skills focused on content management and delivery systems. Such future discussions on expanding the scope of the certificate program, with possible collaboration with other partner universities are warranted.

Coursework Design: Research [4] suggests that TC certificate programs are focused on the following types of courses: 1. General technical communication (including introductory \& advanced technical communication/writing service courses) 2. Editing 3. Technical communication genre courses and 4. Digital technology. The major sections most likely comprise of the following:

- Technical Communication / Technical Writing

- Technical Communication Genre Writing 
- Other Writing

- Editing

- Communication \& Rhetoric

- Management

- Visual Design

- Digital Technology

- Miscellaneous

The comprehensive TC certificate program at the UoA, as it stands now is probably good enough as a starting point, as it has a range of approved courses which are considered relevant for TC certificate by JTCA officials. However, this certificate, when looked at from a standard TC perspective, may appear to be a little disconnected in its focus, mostly because the above-mentioned standard genres are not focused or included in the coursework. Also, for the UoA TC comprehensive certificate program, we have done a repurposing with the existing courses - it refers to the bringing together of existing resources into a new format - essentially redefining their purpose within a new framework. It makes more administrative sense in terms of time saved, money, and energy and helps the department and faculty shine in new ways. However, generating refers to the development of new courses that are designated specifically for the certificate program, but prior to its existence. This effort leads to more interdisciplinary initiatives, and the courses could be more focused on the purpose why they were generated (Bridgeford, 2003) [6]. As the importance of technical and professional communication (TPC) grows in Japan, we may look at courses generated specifically for the certificate program, either at undergraduate or graduate level.

Networking for Establishing the Certificate Program: These are some examples of Technical Writing Associations types needed in Japan for all-round development of the profession.

- Society for Technical Communication (https://www.stc.org/)

- IEEE Professional Communication Society (https://procomm.ieee.org/)

- Institute of Scientific and Technical Communicators (https://istc.org.uk/)

- ACM SIGDOC (http://sigdoc.acm.org/)

- American Medical Writers Association (https://www.amwa.org/)

It will likely make reasonable sense if Japanese universities could collaborate with such organizations when offering the certificate program for raising student awareness about the profession. These associations are involved with many conference hosting activities, seminars, roundtables, post many teaching materials, advertise relevant university programs, interviews with technical communication specialists etc.

In Japan, we only have JTCA - Japan Technical Communicators Association who is taking the initiative to promote such TC comprehensive certificate programs. https://www.t-kougei.ac.jp/activity/research/pdf/vol37-2-02.pdf

Literature discussing the pedagogical design and implications of technical communication certificate programs are scant. Curriculum and instructional designers on the topic, especially in EFL and Japanese educational context would do well to read this article as a case study on how to develop bridging courses, how to design the courses with the certificate in mind, and how to go through the curriculum design and potential administrative challenges. Research by McCraken et al [7] mentioned work done by Johnson, Simmons, and Sullivan [8] who suggested that we should see TC comprehensive certificates as a way of maintaining a sustainable program by making use of existing resources. Such certificates can address what Johnson, Simmons, and Sullivan [8] identify as the "seven tenets" of lean technical communication.

- They intrinsically emphasize value over deficit

- They may innovate and disrupt established approaches to TPC

- They are often rooted in local needs, and are aimed at social responsibility

- They can regulate costs

- They often engage sustainability as impetus for innovation

- They promote efficiency

- They enhance the visibility of programs

Johnson, Simmons, and Sullivan [8] further noted that when considering the sustainability of TPC programs, we should attend to the ecosystems in which they are embedded. At various levels of these ecosystems-the federal, state, institutional, departmental, and programmatic - such TC certificate programs look very different. Finally, curriculum designers of such certificates should read about 23 such TC certificate programs as identified at the undergraduate level as of 1994 [9] and 67 as of 2012 [10]. 


\section{References}

[1] Hazzan, O., \& Har-Shai, G. (2013, March). Teaching computer science soft skills as soft concepts. In Proceeding of the 44th ACM technical symposium on Computer science education (pp. 59-64).

[2] Reave, L. (2004). Technical communication instruction in engineering schools: A survey of top-ranked US and Canadian programs. Journal of Business and technical Communication, 18(4), 452-490.

[3] Starke-Meyerring, D., Duin, A. H., \& Palvetzian, T. (2007). Global partnerships: Positioning technical communication programs in the context of globalization. Technical Communication Quarterly, 16(2), 139-174.

[4] Nugent, J. (2010). 8 Certificate Programs in Technical Writing: Through Sophistic Eyes. Design discourse: Composing and revising programs in professional and technical writing, 153-170.

[5] Etlinger, H. A. (2006, March). A framework in which to teach (technical) communication to computer science majors. In Proceedings of the 37th SIGCSE technical symposium on Computer science education (pp. 122-126).

[6] Bridgeford, T. (2003). Repurposing v. generating: Developing a certificate in technical writing. Complicating Binaries: Exploring Tensions in Technical and Scientific Communication, 79.

[7] McCracken, C., Moeller, M., \& Steiner, L. Certificate Programs and Sustainable TPC. In Proceedings for 2018 CPTSC Annual Conference.

[8] Johnson, M.A. \& Simmons, W.M. \& Sullivan, P. (2018). Lean technical communication: Toward sustainable program innovation. New York: Routledge.

[9] Norman, R., \& Wells, K. P. (1997). Certificate Programs. In M. Keene (Ed.), Education in scientific and technical communication: Academic programs that work (pp.125-149). Arlington, VA: Society for Technical Communication Press.

[10] Meloncon, L. (2012). Current overview of academic certificates in technical and professional communication in the United States. Technical Communication, 59(3), 207-222. 